\title{
Length variation in mtDNA control region in hatchery stocks of European sea bass subjected to acclimation experiments
}

\author{
Giuliana Allegrucci*, Donatella Cesaroni, Federica Venanzetti, \\ Stefano Cataudella, Valerio Sbordoni \\ Department of Biology, Tor Vergata University, \\ via della Ricerca Scientifica, 00133 Rome, Italy
}

(Received 29 May 1997; accepted 17 March 1998)

\begin{abstract}
Length polymorphism of the mtDNA control region was analysed in samples from the sea bass Dicentrarchus labrax before and after acclimation to freshwater. Acclimation trials were repeated twice for two samples originating from the same broodstock. DNA amplification of 221 individuals made it possible to detect 40 different D-loop length variants and a mean level of gene diversity $\left(k_{c}\right)$ of 0.850 . Out of 52 scored distinct genotypes, 18 were homoplasmic and the remaining ones were heteroplasmic for up to four variants. Shifts in frequencies between starting and acclimated samples in the same direction of the same genotypes in both years were not observed. Patterns of mtDNA control region variation were compared to previous allozymic and RAPD studies carried out on the same samples. While variation found in the allozyme alleles and the RAPD markers in replicate experiments revealed differential survival of the genotypes, stochastic processes, such as genetic drift, explained the observed variation of mtDNA control region. Very high levels of genotype diversity were observed within each sample, ranging from 0.77 to 0.97 . This high diversity associated with the maternal inheritance of mtDNA makes this molecular marker especially suitable for studies in aquaculture genetics, when the allozyme studies fail to reveal genetic variation or when the identification of progeny based on the mother's contribution is relevant. (C) Inra/Elsevier, Paris
\end{abstract}

fish mtDNA / D-loop region / European sea bass / hatchery stock / acclimation trials

Correspondence and reprints

E-mail: allegrucci@uniroma2.it 
Résumé - Polymorphisme de la longueur de la région de contrôle de l'ADN mitochondrial dans des souches de bar européen soumis à des expériences d'acclimatation à l'eau douce. Le polymorphisme de longueur de la région de contrôle de l'ADN mitochondrial (ADNmt) a été analysé dans des échantillons de bar $(D$. labrax) avant et après des expériences d'acclimatation à l'eau douce. Les expériences d'acclimatation ont été répétées sur deux échantillons de même origine. L'amplification de l'ADNmt de 221 individus a permis de détecter 40 variantes de longueur de la boucle $\mathrm{D}$ et une diversité génique $\left(K_{c}\right)$ de 0,850 en moyenne. Sur 52 génotypes analysés, 18 ont été homoplasmiques et le reste hétéroplasmiques, avec jusqu'à quatre variants chez le même individu. La variation de la région de contrôle de l'ADNmt a été comparée à celle observée lors d'études précédentes sur les mêmes échantillons pour les allozymes et aux marqueurs RAPD. Alors que la variation liée aux allozymes et aux marqueurs RAPD trouvés a indiqué des différences de survie des génotypes après acclimatation, des processus stochastiques, comme la dérive génétique, peuvent expliquer la variation observée. À l'intérieur de chaque échantillon, on a observé de hauts niveaux de diversité génétique avec une variation comprise entre l'indice 0,77 et l'indice 0,97 . Cette diversité associée à l'hérédité maternelle de l'ADNmt semble rendre ce marqueur moléculaire très utile pour les études génétiques appliquées à la pisciculture. (C) Inra/Elsevier, Paris

\section{poisson / bar / ADN mitochrondrial / D loop / acclimatation}

\section{INTRODUCTION}

The European sea bass, Dicentrarchus labrax, is an Euryhaline species found in the northeastern Atlantic Ocean and in the Mediterranean sea. It occurs in coastal waters, lagoons and estuaries. This species is very important in the fishery industry and is also widely used in aquaculture [7, 26]. The genetic identification and discrimination of aquaculture stocks is a fundamental requirement in culture programmes especially for those directed at using genetically characterized breeders. The knowledge of genetic heterogeneity within and among stocks makes it possible to minimize the deleterious effects of inbreeding and/or specific selective agents by planning appropriate crossing schedules.

For the past few years we have been analysing the distribution of genetic variability in wild and cultivated populations of sea bass $D$. labrax, using different genetic markers, such as allozymes [1, 3], RAPDs [2, 13] and mitochondrial DNA (mtDNA; [14-16, 29].

Over two subsequent years (1989 and 1990) we followed the changes in genetic variation in reared samples, before and after acclimation to freshwater. Both allozyme and RAPD markers showed that survival to acclimation to freshwater was not random. Variability estimates based on 28 allozyme loci decreased between the starting and acclimated samples by about $50 \%$. Survival rates and relative fitnesses per genotype per locus were estimated and in both years the same genotype at certain loci (i.e. $C k-4, E s t-2, G 6 p d, M e, N p$ ) showed the highest probability of survival [1]. Similar shifts were also observed in RAPD markers. Even though only one band out of the 126 markers scored showed concordant shifts in both years, which were statistically significant, several other markers also varied concordantly [2]. These results suggested the hypothesis that regimes associated with acclimation trials, which are selected 
within an heterogeneous array of genotypes, probably reflect the different geographic origins of broodstock $[1,2]$.

We followed the behaviour of both allozymes and RAPD markers in wild populations from the Mediterranean sea, sampled either in open sea or in coastal lagoons. Interestingly, the allozyme genotypes and RAPD bands, which increased in frequency in the samples acclimated to freshwater, were also more frequently found in wild populations from brackish water rather than from the open sea $[3,13]$. Wild populations were also investigated using a third marker, the D-loop or control region of mtDNA, which revealed the existence of length polymorphism [16].

In this paper we analyse the same cultivated samples previously studied by allozymes and RAPDs, studying the length polymorphism of the mtDNA control region, before and after acclimation to freshwater. This region has proven to be particularly suitable for population genetic studies [9], because it has the highest nucleotide substitution rate of all the mitochondrial genome, with an evolutionary rate up to five times higher than the coding portion $[20,30]$. The control region is primarily responsible for the observed variation in the total length of the vertebrate mitochondrial genome (see review in Meyer $[21,22])$. In vertebrates, the D-loop region often varies in length because of tandem duplications $[23,28]$. In fish, length variation is not a rare phenomenon and in most cases it is due to variation in the copy number of tandem repeats in the control region $[5,8,11,12,22,24,31]$. In $D$. labrax, the control region has proven to be only responsible for the observed individual variation in total length of the mtDNA molecule [29]. The sequencing of length variants from three distinct $D$. labrax individuals revealed the existence of a) a variable number of copies of two strictly related 17-bp tandemly repeated sequences; b) a variable number of copies of two strictly related 48-bp tandemly repeated sequences; and c) an 'imperfect' 17 -bp repeat occurring only once in the D-loop region, which separates the array of 17 -bp repeats from the array of the 48 -bp repeats (figure $1 ;$ [15]). A survey of 209 individuals collected in eight Mediterranean localities confirmed that mtDNA length variation in $D$. labrax is the outcome of the contemporary variation in repeat copy number of these two repeat arrays. Moreover, it revealed high levels of heteroplasmy (33.3-70 \%), and genetic diversity, especially between individuals within populations [16].

The aim of the present study was to characterize and quantify length variation in a large sample of reared individuals, in order to evaluate differences after acclimation to freshwater. Comparisons with allozyme and RAPD variation were also carried out, in order to examine the usefulness of the three molecular markers as a source of genetic markers in sea bass aquaculture.

\section{MATERIAL AND METHODS}

Samples were taken from the ENEL fish farms, 'Torrevaldaliga' (Civitavecchia, Latium) and 'La Casella' (Piacenza, Lombardy). Samples from 'Torrevaldaliga' were obtained from artificial reproduction in 1989 and 1990. In both years, the same broodstock, made up of 190 individuals from different localities along the Italian coasts (i.e. $50 \%$ from Thyrrenian sea and $50 \%$ from northern Adriatic sea), contributed to artificial reproduction, the sex ratio being two males to one female. Fingerlings (ca. 60000 per year) were reared in 


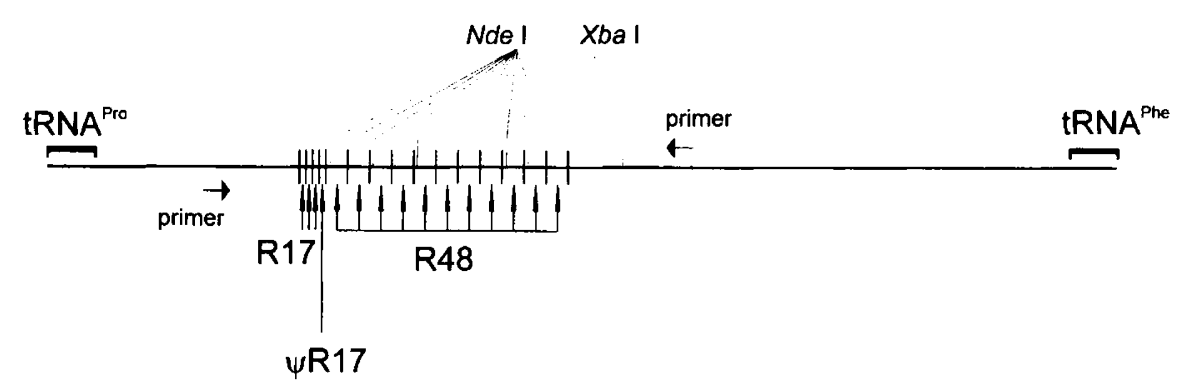

Figure 1. Schematic representation of the D. labrax mitochondrial control region, enclosed between two tRNA genes, showing the R17 and R48 repeat arrays and the unique sequence R17 between them. The position of PCR primers and of Nde $I$ and $X b a I$ restriction sites are also indicated.

seawater conditions up to a size of $70 \mathrm{~g}$ in weight. Average age was 10 months (1989 sample) and 1 year (1990 sample). Yearly samples (ca. 7000 sea basses in 1989 and 2600 in 1990) were taken from this stock and transferred to the ENEL fish farm 'La Casella', where they were acclimated to freshwater (for further details see Allegrucci et al. [1]). At the sampling time (i.e. after 15 months for 1989 sample and 7 months for 1990 one) mortality rates were $94.4 \%$ for 1989 sample and $74.7 \%$ for 1990 one. Starting samples from Torrevaldaliga collected before freshwater acclimation were named S89 for 1989 and S90 for 1990. Samples from La Casella collected after acclimation trials were named A89 for 1989 and A90 for 1990.

DNA was extracted from individual fishes, following a standard phenolchloroform procedure detailed in Allegrucci et al. [2]. We amplified the variable portion of the D-loop region by PCR. Primer sequences were derived from Cecconi et al. [15]. They are complementary to unique sequences flanking the tandem arrays located at positions 284-302 (CCCGAGTGCCACAAACGCG) and positions 1509-1490 (TTGTCCCTGAACTAACAGCC) of the D. labrax D-loop sequence (EMBL Data Library accession no. X81472).

Amplifications were performed with a Perkin-Elmer Cetus thermal cycler in $50 \mu \mathrm{L}$ of a solution containing $10 \mathrm{mM}$ Tris- $\mathrm{HCl}, 50 \mathrm{mM} \mathrm{KCl}, 1.5 \mathrm{mM} \mathrm{MgCl}_{2}$, each dNTP at $2.5 \mathrm{mM}$, about $20 \mathrm{ng}$ of template DNA, 1U of Amplitaq, $15 \mathrm{ng}$ for each of the two primers used. Amplification conditions included a total of 30 cycles of $1 \mathrm{~min}$ at $94^{\circ} \mathrm{C}, 1 \mathrm{~min}$ at $55^{\circ} \mathrm{C}$ and $2 \mathrm{~min}$ and $30 \mathrm{~s}$ at $72{ }^{\circ} \mathrm{C}$, using the fastest available transition between each temperature. Individual PCR amplification products were separated by electrophoresis through ethidiumbromide stained 1-1.5\% agarose gels in Tris-borate buffer and their size was scored in comparison to appropriate molecular weight standards.

Each individual fragment was double digested with the restriction endonucleases $N d e I$, recognizing a site within all the sequences of $\mathrm{R} 48$ repeats, and $X b a I$, which cleaves the amplified region at an unique site $143 \mathrm{bp}$ away from $3^{\prime}$ end (figure 1). After digestion, the products were visualized on $2 \%$ TBE agarose gels and compared to molecular weight standards. As shown in figure 2, from double digestions of each amplified D-loop portion, we always obtained fragments of known length (143 and $163 \mathrm{bp}$ ), $n$ 48-bp-long fragments (not visible 


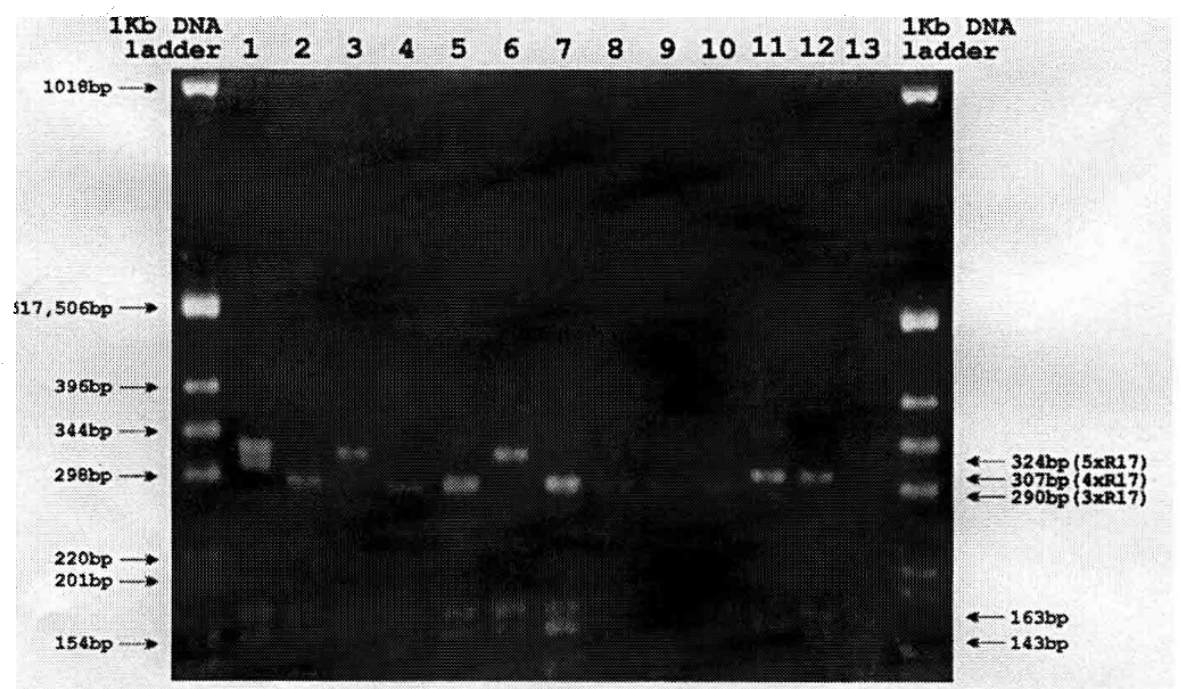

Figure 2. Example of pattern obtained after mtDNA fragments are double digested with the restriction endonucleases $N d e I$ and $X b a I$. See text for details.

in the figure) and a residual fragment whose variable length depends on the number of $\mathrm{R} 17$ repeats. The 143-bp fragment derives from the cleavage site of $X b a I$ away from $3^{\prime}$ end of the amplified region; the 163-bp is comprised on the D-loop map between the $X b a I$ restriction site and the first $N d e I$ site away from $3^{\prime}$ end. Nde I, cleaving once in each R48 repeat, produces $n$ 48-bp fragments. In figure 2, the three fragments of 290,307 and $324 \mathrm{bp}$ (belonging to different individuals) illustrate the length variability of the D-loop fragment including the R17 repeats. Each one of these variable fragments includes the primer (at the $5^{\prime}$ end), $26 \mathrm{bp}$ of the first R48 element and $194 \mathrm{bp}$ (non-repeated sequence between the primer and the first R17 element) for a total of 239 bp plus $n$ R17. The number of $\mathrm{R} 48$ repeats was inferred by comparing the fragment sizes before and after digestion. In fact, the difference in molecular weight among $D$. labrax D-loops is due only to the different composition in number of R17 and/or R48. Once we calculated the repeat combination for each amplified fragment, the molecular weight of each D-loop examined was also indirectly inferred.

The statistical data analysis, i.e. frequency distribution and multivariate analysis were performed by using standard procedures included in the STATISTICA package (ver. 5.1, StatSOFT, Inc. [27]).

Estimates of genetic diversity were calculated within each sample for both length variants and genotypes, according to the general formula $K=1-\Sigma x_{i}^{2}$, where $x_{i}$ is the frequency of the $i$ th size length variant or composite genotype within the sample [10]. Estimates of gene diversity $\left(K_{c}\right)$ were obtained when frequencies of length variants were used and estimates of genotype diversity $(G)$ were obtained when frequencies of composite genotypes were used. Standard errors were estimated using a jackknife procedure within each sample. Each length variant or each genotype in turn was omitted and $K_{c}$ or $G$ was reestimated. For $n$ length variants or $n$ genotypes, one obtains $n$ different 
estimates. The jackknife mean is the average of the $n$ estimates and the jackknife variance is their variance.

Likelihood ratio test analyses were used to determine if the genotype frequencies were significantly different among samples. The exact test was used because the sparseness of data sets, using SPSS package (vers. 6.0, Metha and Patel/SPSS Inc., 1993).

Multivariate ordination of individual fish based on the D-loop genotypes was studied by means of correspondence analysis, using individual profiles. Each individual was characterized for each variable (length variant) as 1 in the presence of the length variant and as 0 in its absence. This analysis was carried out separately on the two yearly samples (S89-A89 and S90-A90, respectively).

\section{RESULTS}

Each individual amplification produced a maximum of four fragments of different lengths, which were interpreted as heteroplasmic variants if they were present in the same individual. In table $I$, the total number of fragments, number of length variants and number of distinct genotypes for each sample (S89, A89, S90 and A90) are reported. Estimates of heteroplasmy within each sample are also reported. The percentage of heteroplasmy was about $30 \%$ in $\mathrm{S} 89, \mathrm{~S} 90$ and $\mathrm{A} 90$ and reached $70 \%$ in $\mathrm{A} 89$.

Table I. Dicentrarchus labrax. Basic data and heteroplasmy in the two yearly samples of sea bass before (S89, S90) and after acclimation (A89, A90) to freshwater.

\begin{tabular}{lclll}
\hline & S89 & A89 & S90 & A90 \\
\hline Sample size & 75 & 50 & 47 & 49 \\
Total fragments & 103 & 90 & 66 & 67 \\
No. length variants & 21 & 13 & 18 & 22 \\
No. distinct genotypes & 25 & 16 & 20 & 20 \\
\% Heteroplasmy & 30.7 & 70.0 & 31.9 & 28.6 \\
\hline
\end{tabular}

Among the 221 specimens of D. labrax analysed, 40 different D-loop length variants were detected. For each variant, the overall size of the amplified product, the number of tandemly repeated R17 and R48 sequences, and the relative frequency in each sample are reported (table $I I)$. The minimum and maximum length of the amplified portions were 884 and $1463 \mathrm{bp}$, respectively. The total length variation was due to the combined variation of the number R17 and R48 repeats, as described in Cesaroni et al. [16]. More than $50 \%$ of the scored D-loop length variants (22 out of 40 ) were singletons, and occurred only in one of the four samples. Between the two yearly samples only 15 out of 40 length variants (35\%) were in common. Starting and acclimated samples within each year shared 21 and $44 \%$ (in 1989 and 1990, respectively) of the Dloop length variants (table $I I$ ). Estimates of gene diversity, $K_{c}$, for this mtDNA region ranged from 0.750 to 0.899 and are reported in table III.

Out of 221 assayed specimens in the two yearly samples, a total of 52 distinct genotypes, named LP1-LP52, were found. Genotypes from LP1 to LP17 were 
Table II. Dicentrarchus labrax. Base pair, R17 and R48 repeat copy number and frequency of length variants (numbered from 1 to 40 ) in the two yearly samples of sea bass before (S89, S90) and after acclimation (A89, A90) to freshwater.

\begin{tabular}{|c|c|c|c|c|c|c|c|}
\hline & $\begin{array}{l}\text { Size } \\
\text { (bp) }\end{array}$ & $\begin{array}{c}\text { Number } \\
\text { R17 }\end{array}$ & $\begin{array}{c}\text { Number } \\
\text { R48 }\end{array}$ & S89 & A89 & S90 & A90 \\
\hline 1) & 1463 & 6 & 18 & 0.019 & 0.000 & 0.000 & 0.000 \\
\hline 2) & 1370 & 9 & 15 & 0.000 & 0.000 & 0.000 & 0.015 \\
\hline 3) & 1364 & 3 & 17 & 0.000 & 0.011 & 0.000 & 0.000 \\
\hline 4) & 1316 & 3 & 16 & 0.019 & 0.000 & 0.000 & 0.015 \\
\hline 5) & 1288 & 7 & 14 & 0.000 & 0.000 & 0.000 & 0.015 \\
\hline 6) & 1280 & 15 & 11 & 0.010 & 0.000 & 0.000 & 0.000 \\
\hline 7) & 1271 & 6 & 14 & 0.029 & 0.000 & 0.000 & 0.075 \\
\hline 8) & 1268 & 3 & 15 & 0.000 & 0.011 & 0.000 & 0.000 \\
\hline 9) & 1263 & 14 & 11 & 0.010 & 0.000 & 0.000 & 0.000 \\
\hline 10) & 1257 & 8 & 13 & 0.000 & 0.000 & 0.000 & 0.015 \\
\hline 11) & 1254 & 5 & 14 & 0.000 & 0.000 & 0.015 & 0.000 \\
\hline 12) & 1226 & 9 & 12 & 0.000 & 0.000 & 0.000 & 0.015 \\
\hline 13) & 1223 & 6 & 13 & 0.019 & 0.000 & 0.000 & 0.015 \\
\hline 14) & 1220 & 3 & 14 & 0.010 & 0.000 & 0.000 & 0.000 \\
\hline 15) & 1192 & 7 & 12 & 0.000 & 0.000 & 0.015 & 0.000 \\
\hline 16) & 1189 & 4 & 13 & 0.000 & 0.011 & 0.000 & 0.000 \\
\hline 17) & 1181 & 12 & 10 & 0.010 & 0.000 & 0.000 & 0.000 \\
\hline 18) & 1178 & 9 & 11 & 0.000 & 0.000 & 0.000 & 0.015 \\
\hline 19) & 1175 & 6 & 12 & 0.000 & 0.000 & 0.045 & 0.000 \\
\hline 20) & 1172 & 3 & 13 & 0.029 & 0.067 & 0.030 & 0.015 \\
\hline 21) & 1141 & 4 & 12 & 0.019 & 0.044 & 0.030 & 0.075 \\
\hline 22) & 1127 & 6 & 11 & 0.000 & 0.000 & 0.015 & 0.000 \\
\hline 23) & 1124 & 3 & 12 & 0.194 & 0.344 & 0.167 & 0.224 \\
\hline 24) & 1110 & 5 & 11 & 0.010 & 0.000 & 0.076 & 0.030 \\
\hline 25) & 1093 & 4 & 11 & 0.049 & 0.111 & 0.167 & 0.119 \\
\hline 26) & 1076 & 3 & 11 & 0.058 & 0.333 & 0.076 & 0.104 \\
\hline 27) & 1062 & 5 & 10 & 0.000 & 0.000 & 0.227 & 0.045 \\
\hline 28) & 1045 & 4 & 10 & 0.019 & 0.000 & 0.015 & 0.000 \\
\hline 29) & 1028 & 3 & 10 & 0.039 & 0.011 & 0.015 & 0.045 \\
\hline 30) & 1017 & 8 & 8 & 0.000 & 0.011 & 0.000 & 0.000 \\
\hline 31) & 1014 & 5 & 9 & 0.000 & 0.000 & 0.015 & 0.000 \\
\hline 32) & 1000 & 7 & 8 & 0.000 & 0.011 & 0.000 & 0.000 \\
\hline 33) & 997 & 4 & 9 & 0.000 & 0.000 & 0.015 & 0.015 \\
\hline 34) & 980 & 3 & 9 & 0.078 & 0.000 & 0.045 & 0.015 \\
\hline 35) & 969 & 8 & 7 & 0.000 & 0.011 & 0.000 & 0.000 \\
\hline 36) & 952 & 7 & 7 & 0.000 & 0.022 & 0.000 & 0.000 \\
\hline 37) & 949 & 4 & 8 & 0.049 & 0.000 & 0.000 & 0.045 \\
\hline 38) & 932 & 3 & 8 & 0.078 & 0.000 & 0.015 & 0.015 \\
\hline 39) & 901 & 4 & 7 & 0.243 & 0.000 & 0.015 & 0.075 \\
\hline 40) & 884 & 3 & 7 & 0.010 & 0.000 & 0.000 & 0.000 \\
\hline
\end{tabular}

homoplasmic. Heteroplasmic genotypes with two bands were named LP18LP39. Eleven genotypes were made up of three fragments (LP40-LP50) and only two genotypes (LP51 and LP52) were heteroplasmic for four fragments. Heteroplasmic individuals with three or four bands were rare, and they were very often singletons (figure 2). 
Mean genotype diversity estimates, $G$, calculated for each sample, indicated a reduction between starting and acclimated samples in 1989 ( $G_{\mathrm{S} 89}=$ $\left.0.865 \pm 0.0004, G_{\mathrm{A} 89}=0.772 \pm 0.001\right)$ and a slight increase in the 1990 sample $\left(G_{\mathrm{S} 90}=0.876 \pm 0.0006, G_{\mathrm{A} 90}=0.911 \pm 0.0004\right)$. Although genotype diversity estimates were rather similar in both years, the pattern of distribution of the D-loop genotypes was remarkably different (figure 3). In 1989, only six out of 35 genotypes were shared by the two samples, S89 and A89, before and after acclimation to freshwater. The other genotypes either in the starting sample or in the acclimated one were mostly singletons. In 1990, 9 out of 30 genotypes were in common between the S90 and A90 samples, before and after acclimation to freshwater. The other genotypes occurred in one or at least two individuals either in the starting sample or in the acclimated one. Between the two yearly samples only 13 out of 52 genotypes were in common, although diversity estimates were similarly high (table III). In both years, only a few genotypes had a high frequency of occurrence ( $\geq 10 \%$ ). In 1989, four genotypes (LP1, LP8, LP10 and LP19) were the most common. In 1990, three genotypes (LP6, LP8 and LP10) had frequencies higher than $10 \%$. Only the LP8 and LP10 genotypes were frequent in both years (figure 3).

Likelihood ratio tests were carried out to evaluate differences in genotype frequencies between starting and acclimated samples and between the two yearly samples. Statistically significant differences (exact probability, $P<<0.01$ were observed between all samples, except for the S90/A90 comparison which showed an exact probability equal to 0.087 .

Results from the multivariate correspondence analysis, carried out on individual D-loop genotype profiles, did not reveal any shift in genotype frequencies between the starting and acclimated samples in both years.

\section{DISCUSSION}

\subsection{Levels of genetic variation}

The results of this study confirmed the occurrence of high levels of length polymorphism in the mtDNA D-loop region of D. labrax, as already observed in wild populations [16]. The high variation in copy number of both the R17 and R48 repeats, associated with the high degree of heteroplasmy found in D. labrax populations, were probably responsible for the high number of distinct genotypes found either in the wild populations or in the cultivated samples.

Statistically significant differences were found between the genotype frequency distribution of the two yearly samples (exact probability $<<0.01$, figure 3). This suggested that these samples, since mtDNA is maternally inherited, originated from genetically different maternal lines within the same broodstock. This result is in agreement with those obtained from allozyme and RAPD markers analyses, carried out on the same individuals [1, 2]. As with allozymes and RAPD markers, the D-loop length variation suggested that the two starting populations were genetically heterogeneous. Indeed, the original broodstock was heterogeneous, as it was composed of individuals from different geographic populations from Italian coastal waters.

When the levels of diversity of the hatchery stock samples were compared with those from wild populations, a reduction in the amounts of D-loop 
Starting Samples

Acclimated Samples
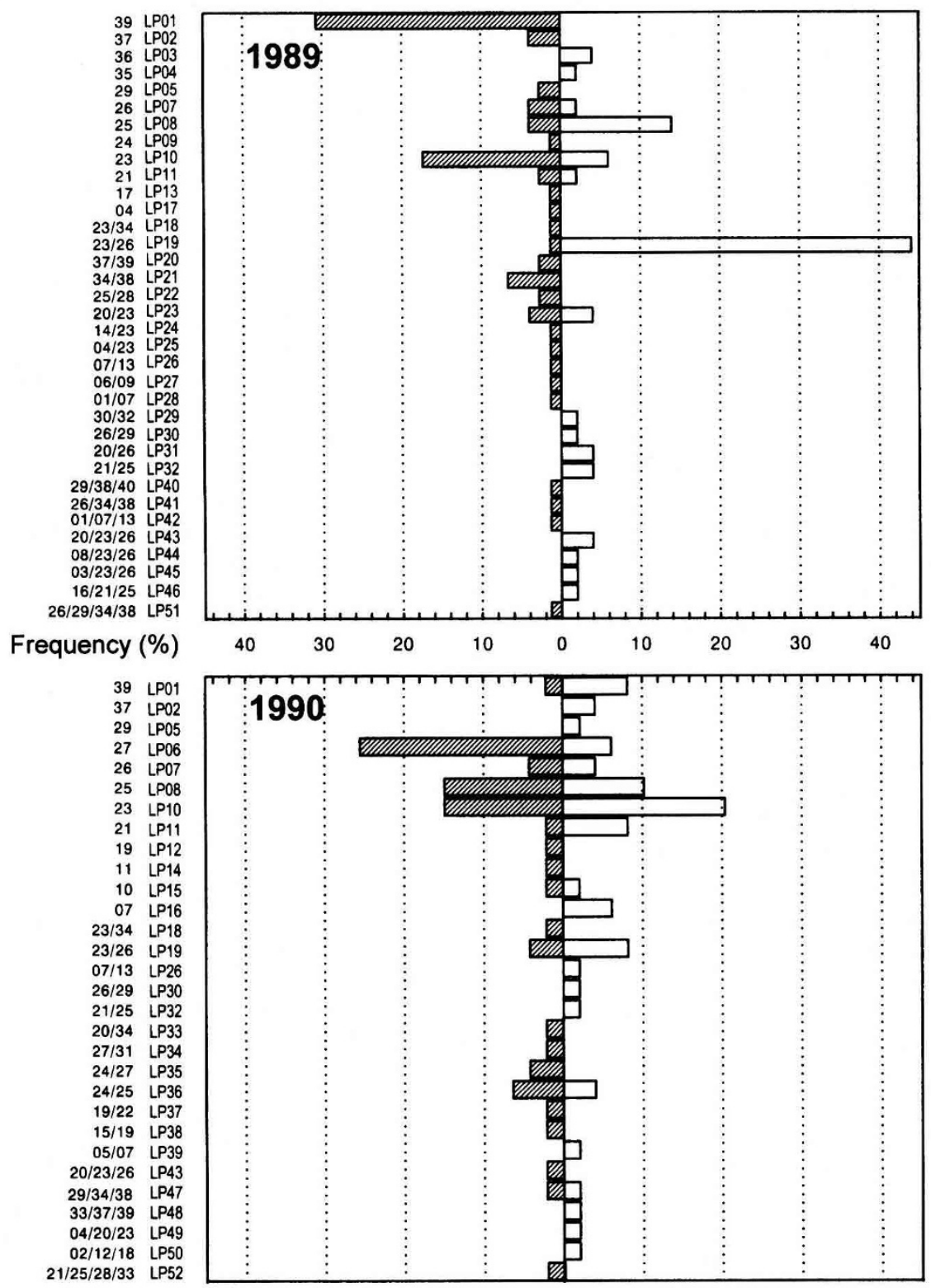

Figure 3. Observed frequencies of D-loop genotypes in the two yearly samples of D. labrax before and after acclimation to freshwater. Genotypes are named LP1-LP52 and next to each genotype symbol the number and type of length variants is shown (see table II for correspondance). 
Table III. Dicentrarchus labrax. Estimates of gene $\left(K_{c}\right)$ and genotype $(G)$ diversities in the two yearly samples of sea bass before (S89, S90) and after acclimation (A89, A90) to freshwater. Standard errors, obtained by jackknife procedure, are also indicated.

\begin{tabular}{lcc}
\hline & $K_{\mathrm{c}} \pm$ Std error & $G \pm$ Std error \\
\hline S89 & $0.878 \pm 0.0002$ & $0.865 \pm 0.0004$ \\
A89 & $0.750 \pm 0.0003$ & $0.771 \pm 0.0011$ \\
S90 & $0.873 \pm 0.0003$ & $0.875 \pm 0.0006$ \\
A90 & $0.898 \pm 0.0003$ & $0.911 \pm 0.0004$ \\
\hline
\end{tabular}

length variation could be observed. The study of wild populations coming from eight Mediterranean localities, ranging from France (Gulf of Lyons) to Egypt (Bardawill lagoon), revealed a total of 104 D-loop length variants and an average level of gene diversity, $K_{c}$, equal to $0.937 \pm 0.013$ [16]. As previously pointed out, the cultivated samples of sea bass originated from a broodstock composed of individuals belonging to different Italian populations both from Adriatic and Thyrrenian seas. Unfortunately, we did not analyse the mtDNA length variation in any other Adriatic populations. We could only compare the genetic diversity between hatchery stock samples and wild populations, by using the wild populations coming from Thyrrenian sea. The four Thyrrenian populations showed 76 length variants across 121 assayed individuals and an average level of gene diversity, $K_{c}$, equal to $0.930 \pm 0.022$. The cultured stock showed a significant reduction in mtDNA length variation with respect to the wild populations, having only 40 D-loop length variants over 221 specimens, with a $K_{c}$ of $0.850 \pm 0.033$.

The reduction in genetic variability in cultivated stocks of aquatic organisms is a known phenomenon. This reduction can be due to the limited number of founding parents relative to wild populations, where genetic drift mediated by reductions in effective population size can cause lower levels of observed genetic variation [4]. Studies carried out on wild and cultured stocks of salmonids by restriction fragment length polymorphisms (RFLPs) in mtDNA demonstrated the existence of lower variation in cultured stocks. For example, Ontario aquaculture stocks of rainbow trout (Onchorhynchus mykiss) showed an average nucleon diversity less than one-half of that of the wild populations [17]. Swedish stocks of brown trout have only $25 \%$ of the mtDNA variability of the wild populations [19]. The loss of diversity in D. labrax is probably due to domestication. However, we do not know the level of variation in the Adriatic populations. If they have less variation than the Thyrrenian ones, this could also explain the reduced polymorphism levels of the cultured stocks.

When analysing allozyme polymorphisms of wild and hatchery stocks of D. labrax, we did not observe a loss of genetic variation, in fact the average allozyme heterozygosity was of the same order of magnitude in both the hatchery and the wild stocks of sea bass (average heterozygosity was of about $10 \%$; $[1,3])$. Ferguson et al. [17] reported similar results in Onchorhyncus mykiss, with aquaculture stocks not having reduced enzyme heterozygosity relative to the wild populations. 
A possible explanation of these data can be found in the properties of the mtDNA. It is predominantly inherited maternally and no recombination between mitochondrial genomes is known [6]. These factors contribute to the reduction of the effective population size for mtDNA with respect to that for the nuclear genes of the same organisms (generally, in case of a 1:1 sex ratio, the effective population size is one-fourth of that for nuclear genes; [25]) and make it more susceptible to genetic drift and founder effect.

\subsection{D-loop length variation versus rapid and allozyme polymorphisms}

As previously pointed out, the same individuals were studied for allozymic and RAPD variation [1, 2]. Multivariate ordination analysis (correspondence analysis) was carried out for each of the three data sets. Using the first principal axis score as a synthetic descriptor of variation expressed by each genetic marker, we were able to compare the results from the three different molecular techniques. Using the three synthetic descriptors as dimensional axes of a $3 \mathrm{D}$ space, we obtained a schematic representation of the cumulative genetic variation in sea bass (figure 4). Using the axis relative to D-loop genotype variation, it was not possible to distinguish between starting and acclimated samples in both years. This outcome contrasts with those from RAPDs and, especially, allozymes, where a clear separation can be observed in both years (figure 4). RAPD markers and allozyme loci revealed a differential survival rate for the different genotypes to acclimation to freshwater, because some of the RAPD bands and most of the allozyme alleles changed in the same direction in both years. On the basis of these results, we have suggested that selection was responsible for the observed shifts in frequencies in these markers $[1,2]$. In the mtDNA control region, we also only observed statistically significant differences in genotype frequencies between starting and acclimated samples in 1989 (exact $P<<0.01$, figure 3). Differences between starting and acclimated samples were also found in 1990, although they were not significant (exact $P=0.08$, figure 3). However, we did not observe shifts in frequencies in the same direction of the same genotypes in both years.

This result is not surprising if one considers that these three genetic markers are marking different parts of the genome. Allozymes are parts of the functional genome and therefore they are more probably subjected to selective pressures. RAPD markers are, by definition, randomly amplified and most of them may mark less functional parts of the genome and thus are not expected to trace selective effects. The control region of mtDNA (D-loop) is a non-coding region of the mitochondrial genome and is more likely to be neutral than allozymes. On the other hand, specific D-loop genotypes could in principle be linked to genes subjected to selection. However, selection would have to be very strong in order to overcome genetic drift because the effective population size of mtDNA is much lower than that of nuclear genes.

In conclusion, the mtDNA control region did not give any indication of selection acting on sea bass during the acclimation to freshwater. However, the high levels of genotype diversity observed in hatchery stock (table III) and in wild populations of sea bass [16] make this molecular marker very helpful in aquaculture genetics where the identification of progeny based on the 

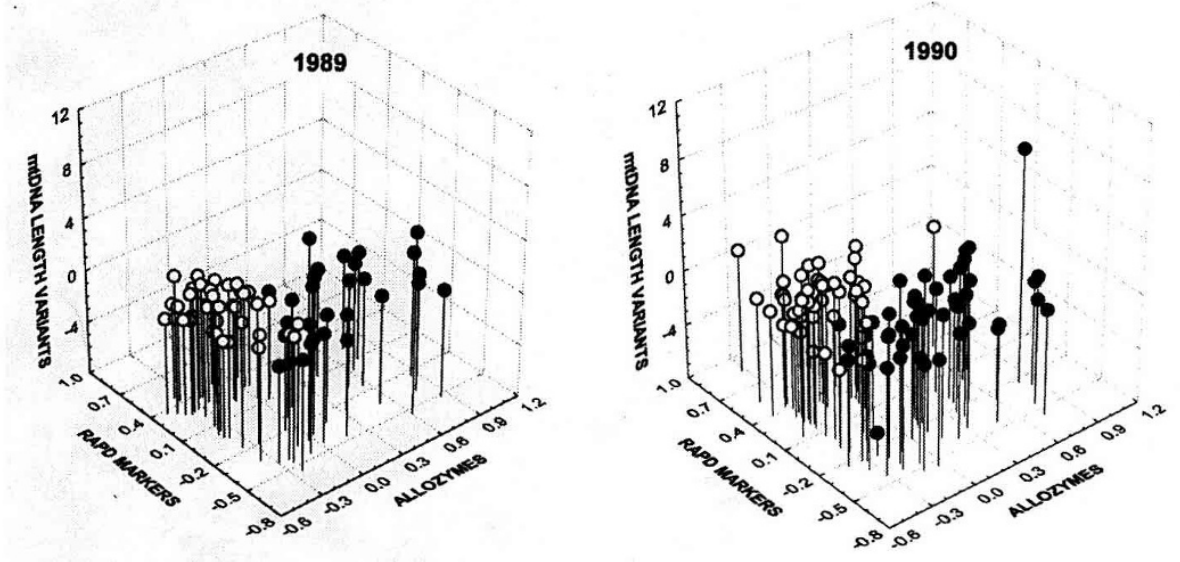

Figure 4. A three-dimensional plot of $D$. labrax specimens in the two yearly samples before (black circles) and after (white circles) acclimation to freshwater. The three coordinates are the first principal axes obtained from correspondence analyses of each set of genetic descriptors (allozymes, RAPD markers and mtDNA length variants, respectively). See text for details.

mother contribution may be relevant. Wild populations show genotype diversity ranging from 0.855 to 0.967 , comparable to that obtained in the present paper for starting samples (table III). Such high diversity within populations ensures a probability of $73-93.5 \%$ for identifying any individual by a given genotype. Moreover, this level of polymorphism is comparable to that observed in a single microsatellite locus [18]. When studying reared and wild stock of species of economic relevance such as $D$. labrax, the opportunity of individual characterization could be beneficial.

The combined study of highly variable markers, such as mtDNA control region and microsatellites would be highly desirable in aquaculture programmes, for three major reasons: a) both these molecular techniques use a PCR mediated approach which has the advantage of characterizing samples by taking tissue biopsies from reared specimens without sacrificing them; b) the analysis of nuclear loci, such as microsatellites, could be used as a complement to avoid the bias of using only one maternally inherited genetic marker; and c) it could provide information on both maternal and paternal genetic contribution in reared stocks. Such information could be useful for reconstructing pedigrees of cultured stocks, which are essential for identifying founder individuals, avoiding deleterious inbreeding and maintaining variability by maximizing founder contributions.

\section{ACKNOWLEDGEMENTS}

The authors gratefully acknowledge Dr P. Bronzi for providing the sea bass samples. Acclimation trials of sea bass were carried out with a EEC grant to S. Cataudella. A. Caccone and C. Fortunato provided the DNA aliquots. Likewise we are very grateful 
to A. Caccone for useful hints on this work and to G. Carchini who suggested the use of the Exact test. C. Di Russo helped us to write the summary in French. This research was supported by a National Research Council grant to V. Sbordoni, Special Project, RAISA, Sub-project n.3.

\section{REFERENCES}

[1] Allegrucci G., Fortunato C., Cataudella S., Sbordoni V., Acclimation to fresh water of the sea bass: evidence of selective mortality of allozyme genotypes, in: Beaumont A.R. (Ed.), Genetics and Evolution of Aquatic Organisms, Chapman and Hall, London, 1994, pp. 486-502.

[2] Allegrucci G., Caccone A., Cataudella S., Powell J.R., Sbordoni V., Acclimation of the European sea bass to freshwater: monitoring genetic changes by RAPD polymerase chain reaction to detect DNA polymorphisms, Mar. Biol. 121 (1995) 591-599.

[3] Allegrucci G., Fortunato C., Sbordoni V., Genetic structure and allozyme variation of sea bass (Dicentrarchus labrax and D. punctatus) in the Mediterranean Sea, Mar. Biol. 128 (1997) 347-358.

[4] Allendorf F.W., Ryman N., Genetic management of hatchery stocks, in: Ryman N., Utter F. (Eds.), Population Genetics and Fishery Management, University of Washington Press, Seattle, WA, 1987, pp. 141-159.

[5] Arnason E., Rand D.M., Heteroplasmy of short tandem repeats in mitochondrial DNA of Atlantic cod, Gadus morhua, Genetics 132 (1992) 211-220.

[6] Avise J.C., Molecular Markers, Natural History and Evolution, Chapman and Hall, New York, 1994.

[7] Barnabé G., Billard R., L'Aquaculture du Bar et des Sparidés, Inra Publ., Paris, 1984.

[8] Bentzen P., Legget W.C., Brow G.G., Length and restriction site heteroplasmy in the mitochondrial DNA of American shad (Alosa sapidissima), Genetics 118 (1988) 509-518.

[9] Billington N., Hebert P.D.N., Mitochondrial DNA diversity in fishes and its implications for introductions, Can. J. Fish. Aquat. Sci. 48 (suppl. 1) (1991) 80-94.

[10] Birky C.W. Jr, Fuerst P., Maruyama T., Organelle gene diversity under migration, mutation and drift: equilibrium expectations, approach to equilibrium, effects of heteroplasmic cells, and comparisons to nuclear genes, Genetics 121 (1989) 613-627.

[11] Brown J.R., Beckenbach A.T., Smith M.J., Mitochondrial DNA length variation and heteroplasmy in populations of White sturgeon (Acipenser transmontanus), Genetics 132 (1992) 221-228.

[12] Buroker N.E., Brown J.R., Gilbert T.A., O'Hara P.J., Beckenbach A.T., Thomas W.K., Smit M.J., Length heteroplasmy of sturgeon mitochondrial DNA: an illegitimate elongation model, Genetics 124 (1990) 157-163.

[13] Caccone A., Allegrucci G., Fortunato C., Sbordoni V., Genetic differentiation within the European sea bass (D. labrax) as revealed by RAPD-PCR assays, J. Hered. 88 (1997) 316-324.

[14] Cecconi F., Venanzetti F., Mariottini P., Sequence of the mitochondrial tRNAThr and tRNAPro genes from European sea bass Dicentrarchus labrax, Nucleic Acids Res. 21 (1993) 2253.

[15] Cecconi F., Giorgi M., Mariottini P., Unique features in the mitochondrial D-loop region of the European sea bass Dicentrarchus labrax, Gene 160 (1995) 149-155. 
[16] Cesaroni D., Venanzetti F., Allegrucci G., Sbordoni V., MtDNA length variation and heteroplasmy in natural populations of European sea bass, Dicentrarchus labrax, Mol. Biol. Evol. 14 (1997) 560-568.

[17] Ferguson M.M., Danzmann R.G., Arndt S.K.A., Mitochondrial DNA and allozyme variation in Ontario cultured rainbow trout spawning in different seasons, Aquaculture 117 (1993) 237-259.

[18] Garcìa de Léon F.J., Chikhi L., Bonhomme F., Microsatellite polymorphism and population subdivision in natural populations of European sea bass Dicentrarchus labrax (Linnaeus, 1758), Mol. Ecol. 6 (1997) 51-62.

[19] Gyllensten U., Wilson A., Mitochondrial DNA of salmonids: inter- and intraspecific variability detected with restriction enzymes, in: Ryman N., Utter F. (Eds.), Population Genetics and Fishery Management, University of Washington Press, Seattle, WA, 1987, pp. 301-317.

[20] Horai S., Hayasaka K., Intraspecific nucleotide sequence differences in the major non coding region of human mitochondrial DNA, Am. J. Hum. Genet. 46 (1990) 828-842.

[21] Meyer A., Evolution of mitochondrial DNA in fishes, in: Hochachka P.W., Mommsen T.P. (Eds.), Biochemistry and Molecular Biology of Fishes, Elsevier Press, 1993, pp. 1-38.

[22] Meyer A., Molecular phylogenetic studies of fish, in: Beaumont A.R. (Ed.), Genetics and Evolution of Aquatic Organisms, Chapman and Hall, London, 1994, pp. $122-249$.

[23] Moritz C., Brown W.M., Tandem duplications in animal mitochondrial DNAs: variation in incidence and gene content among lizards, Proc. Natl. Acad. Sci. USA 84 (1987) 7183-7187.

[24] Mulligan T.J., Chapman R.W., Mitochondrial DNA analysis of Chesapeake Bay White perch Morone americana, Copeia 1989 (1989) 679-688.

[25] Nei M., Tajima F., DNA polymorphism detectable by restriction endonucleases, Genetics 97 (1981) 145-163.

[26] Pickett G.D., Pawson M.G., Sea bass. Biology, exploitation and conservation, in: Fish and Fishery series 12, Chapman and Hall, London, 1994.

[27] StatSoft Inc., STATISTICA for Windows, Statsoft, Inc., 2300 East 14th street, Tulsa, OK, 1996.

[28] Stewart D.T., Baker A.J., Patterns of sequence variation in the mitochondrial D-loop region of shrews, Mol. Biol. Evol. 11 (1994) 9-21.

[29] Venanzetti F., Cecconi F., Giorgi M., Cesaroni D., Sbordoni V., Mariottini P., Cloning and characterization of the European seabass, Dicentrarchus labrax, mitochondrial genome, Curr. Genet. 26 (1994) 139-145.

[30] Vigilant L., Stoneking H., Harpending K., Hawkes K., Wilson A.C., African populations and the evolution of human mitochondrial DNA, Science 253 (1991) 1503-1507.

[31] Wirgin I.I., Proenca R., Grossfield J., Mitochondrial DNA diversity among populations of striped bass in the southeastern United States, Can. J. Zool. 67 (1989) 891-907. 